\title{
The Use of Extubation Readiness Parameters: A Survey of Pediatric Critical Care Physicians
}

\author{
Maroun J Mhanna MD MPH, Ingrid M Anderson MD, \\ Narayan P Iyer MD, and Amy Baumann
}

\begin{abstract}
BACKGROUND: The pediatric literature addressing extubation readiness parameters and strategies to wean from mechanical ventilation is limited. METHODS: We designed a survey to assess the use of extubation readiness parameters among pediatric critical care physicians at academic centers in the United States. RESULTS: The overall response rate was 44.1\% (417/945). The majority of respondents check for air leak and the amount of tracheal secretions. Fewer respondents use sedation score, the rapid shallow breathing index, or the airway-occlusion pressure $0.1 \mathrm{~s}$ after the start of inspiratory flow prior to extubation. The majority perform a spontaneous breathing trial with pressure support. The majority consider $30 \mathrm{~cm} \mathrm{H}_{2} \mathrm{O}$ as the upper limit of an air leak test, and the need for endotracheal suctioning once every 2-4 hours as acceptable for extubation. In preparation for termination of mechanical ventilation the majority daily wean the ventilator rate and/or the pressure support instead of conducting a spontaneous breathing trial. CONCLUSIONS: Most pediatric critical care physicians reported assessing extubation readiness by checking air leak and suctioning need, and less often consider or perform sedation score or the rapid shallow breathing index. Key words: pediatric critical care; extubation readiness; rapid shallow breathing index; sedation score; tracheal secretions; air leak. [Respir Care 2014;59(3):334-339. (C) 2014 Daedalus Enterprises]
\end{abstract}

\section{Introduction}

The number of mechanically ventilated children is increasing, along with an increase in healthcare cost in the United States. Over the last decade the estimated number of children requiring intubation and mechanical ventilation has increased by $11 \%$; however, this increase in healthcare demand was associated with a disproportional in-

The authors are affiliated with the Division of Pediatric Critical Care, Department of Pediatrics, MetroHealth Medical Center, Cleveland, Ohio, with the exception of Dr Anderson, who is affiliated with Rainbow Babies and Children's Hospital, Cleveland, Ohio.

Supplementary material related to this paper is available at http:// www.rcjournal.com.

The authors have disclosed no conflicts of interest.

Correspondence: Maroun J Mhanna MD MPH, Department of Pediatrics, MetroHealth Medical Center, 2500 MetroHealth Drive, Cleveland OH 44109. E-mail: mmhanna@metrohealth.org.

DOI: $10.4187 /$ respcare. 02469 crease in healthcare cost, by $97 \% .^{1,2}$ Therefore interventions to improve care at lower cost are needed. For instance, timely extubation, as determined by extubation readiness parameters, may prevent ventilator-associated complications, decrease days of mechanical ventilation, improve care, and lower cost.

While invasive mechanical ventilation is often lifesaving, it can be associated with complications such as ventilator-induced lung injury, ventilator-associated pneumonia, and endotracheal-tube-associated airway injuries. ${ }^{3}$

See the Related Editorial on Page 445

Therefore it is important that mechanical ventilation be discontinued as soon as the patient can sustain spontaneous breathing without assistance. However discontinuing mechanical ventilation prematurely is associated with morbidity and mortality in adults and children. ${ }^{4-8}$ In children, half of the unplanned or accidental self-extubations are successful, implying that many pediatric patients are ventilated for an excessive period of time. ${ }^{9}$ On the other hand, 
the rate of failed planned extubation in pediatric patients is 2-20\%. ${ }^{3}$ Identifying parameters that reliably predict readiness for extubation would improve the quality of care and decrease morbidity and complications related to mechanical ventilation. Studies in adults ${ }^{10,11}$ and pediatric patients ${ }^{12,13}$ have shown that patients who pass a spontaneous breathing trial (SBT) undergo an extubation readiness trial; $50-75 \%$ are considered ready for extubation. We designed and conducted a survey to determine the frequency of use of extubation readiness parameters such as air leak, rapid shallow breathing index (RSBI), airwayocclusion pressure $0.1 \mathrm{~s}$ after the start of inspiratory flow $\left(\mathrm{P}_{0.1}\right)$, and quantification of secretions and sedation, ${ }^{3}$ the methods used, and the attitudes toward these parameters among pediatric critical care physicians.

\section{Methods}

This study was approved by the institutional review board of MetroHealth Medical Center. Consent was sought in the first e-mail, and response to the survey was deemed consent.

\section{Development of the Survey}

The survey was designed to assess pediatric critical care physicians' familiarity with, attitudes towards, and frequency of use of extubation readiness parameters. ${ }^{14}$ The survey requested demographic data, characteristics of the ICUs, and the respondents' best guesses about the percentage of extubation failure in their units. Extubation failure was defined as the need for reintubation within 48 hours following extubation. The survey asked about 5 extubation readiness parameters: air leak test (ie, air escaping around the endotracheal tube), measurement of the amount of tracheal secretions, RSBI, $\mathrm{P}_{0.1}$, and sedation score. The survey also asked about the use of SBTs and strategies to wean from mechanical ventilation.

The survey had 19 questions (see the supplementary materials at http://www.rcjournal.com). Familiarity with the extubation readiness parameters and methods used to perform these parameters were assessed.

Attitude toward the extubation readiness parameters was assessed with a 5-point Likert scale ranging from strongly disagree to strongly agree. The decision to use and the frequency of use of the extubation readiness parameters were assessed with a 7-point Likert scale ranging from never to always. The survey also asked whether the respondents used daily weaning of ventilator settings or daily SBT.

\section{Study Population}

We surveyed pediatric critical care physicians who work in United States hospitals that have pediatric residency programs. The hospitals were identified from the Ameri-

\section{QUICK LOOK}

\section{Current knowledge}

In adults, weaning-readiness screening and daily spontaneous breathing trials to assess readiness for discontinuation of mechanical ventilation are well described, but there have been few pediatric studies of extubation readiness parameters and weaning strategies.

\section{What this paper contributes to our knowledge}

A majority of pediatric critical care physicians reported assessing extubation readiness by checking for air leak and suctioning requirements, and less often considered or performed sedation score or rapid shallow breathing index during spontaneous breathing.

can Medical Association's Fellowship and Residency Electronic Interactive Database (https://freida.ama-assn.org) of accredited graduate medical education programs and specialty programs in the United States. The names and e-mails of pediatric critical care physicians were then retrieved from the identified hospitals' web sites.

\section{Administration of the Survey}

We used an online survey system (SurveyMonkey, www.surveymonkey.com). The invitation e-mails each had a unique link to the survey. For people who did not respond in 2 weeks, 2 additional invitation e-mails were sent, 2 weeks apart. The survey was initially posted on March 3, 2011, and it was followed by 2 reminders, 2 weeks apart. The survey was closed on April 24, 2011.

\section{Statistical Analysis}

The data are expressed as mean $\pm \mathrm{SD}$. To calculate differences in agreement about conduct or using the extubation readiness parameters we used the non-parametric Friedman 2-way analysis of variance by rank, grouping all the physicians. Such analysis was important to grade the strength of agreement to conduct or use each extubation readiness parameter in comparison to the other parameters, to develop a potential scoring system for extubation readiness in the future. Parameters with high values will weigh differently in the scoring system than parameters with low values. A chi-square test was used to compare categorical data. A $P$ value $<.05$ was considered statistically significant. We used statistics software (SPSS 19, SPSS, Chicago, Illinois) for the analysis. To assess the consistency among individual institutions with multiple ( $\geq 5$ ) respondents, a coefficient of variation was calculated for each question addressed to physicians who belonged to a given institution. 
Table 1. Characteristics of the Physician Respondents and Their Pediatric ICUs

\begin{tabular}{|c|c|c|c|}
\hline & Respondents & $\begin{array}{l}\text { Respondents } \\
\text { Who Answered } \\
\text { This Question }\end{array}$ & Percent \\
\hline \multicolumn{4}{|c|}{ Age range, y } \\
\hline $30-40$ & 157 & 416 & 37.7 \\
\hline $41-50$ & 163 & 416 & 39.2 \\
\hline $51-60$ & 81 & 416 & 19.5 \\
\hline$>60$ & 15 & 416 & 3.6 \\
\hline Male & 261 & 414 & 63 \\
\hline Female & 153 & 414 & 37 \\
\hline \multicolumn{4}{|c|}{ Years of practice } \\
\hline$<5$ & 99 & 416 & 23.8 \\
\hline $5-10$ & 112 & 416 & 26.9 \\
\hline$>10$ & 205 & 416 & 49.3 \\
\hline \multicolumn{4}{|c|}{ Board certified } \\
\hline Yes & 381 & 414 & 92 \\
\hline No & 33 & 414 & 8 \\
\hline \multicolumn{4}{|c|}{ Number of beds } \\
\hline$<10$ & 18 & 416 & 4.3 \\
\hline $10-15$ & 76 & 416 & 18.3 \\
\hline $16-20$ & 95 & 416 & 22.8 \\
\hline$>20$ & 227 & 416 & 54.6 \\
\hline \multicolumn{4}{|c|}{ Presence of fellows } \\
\hline Yes & 273 & 413 & 66.1 \\
\hline No & 140 & 413 & 33.9 \\
\hline \multicolumn{4}{|c|}{$\begin{array}{c}\text { Reported extubation } \\
\text { failure rate, } \%\end{array}$} \\
\hline$<5$ & 185 & 417 & 44.4 \\
\hline $5-10$ & 186 & 417 & 44.6 \\
\hline $11-15$ & 31 & 417 & 7.4 \\
\hline $16-20$ & 6 & 417 & 1.4 \\
\hline
\end{tabular}

\section{Results}

We identified 1,089 physicians, and were able to obtain e-mail addresses for 976 physicians. Sixteen physicians opted out of the survey. Fifteen e-mail addresses bounced back. The overall response rate was $44.1 \%$ (417/945), and $78 \%$ (120/154) of the institutions had at least one responder. The respondents' demographics and pediatric ICU characteristics are summarized in Table 1 .

\section{Familiarity With Extubation Readiness Tests and Methods}

The majority of physicians, $86 \%$ (352/407), check for air leak prior to extubation; $38.5 \%$ (157/409) reported $20 \mathrm{~cm} \mathrm{H}_{2} \mathrm{O}$ as the acceptable upper limit, and $44.5 \%$ (182/409) reported $30 \mathrm{~cm} \mathrm{H}_{2} \mathrm{O}$ as the acceptable upper limit for an air leak test. Overall, $83 \%$ (339/409) consider up to $30 \mathrm{~cm} \mathrm{H}_{2} \mathrm{O}$ as the upper limit for an air leak prior to extubation.

Forty-seven percent (193/410) of the respondents consider suctioning once every 2 hours as acceptable, $22.4 \%$

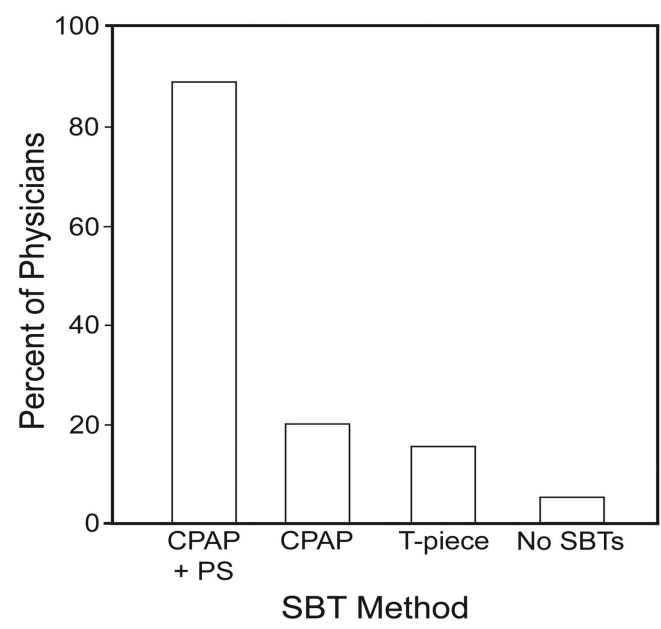

Fig. 1. Percentages of pediatric critical care physicians who reported performing spontaneous breathing trials (SBTs) with CPAP and pressure support (PS), with CPAP only, and with T-piece only, and who do not perform SBTs.

(92/410) consider once every 3-4 hours as acceptable, and $20 \%(82 / 410)$ consider once every hour as acceptable. Overall, $69.5 \%$ (285/410) consider suctioning once every 2-4 hours as acceptable, and 89.5\% (367/410) check for endotracheal secretions prior to extubation.

The majority of the responders, 97\% (401/415), do not perform the $\mathrm{P}_{0.1}$ test. Among the 3\% (14/415) of respondents who do measure $\mathrm{P}_{0.1}, 43 \%(6 / 14)$ consider a $\mathrm{P}_{0.1}$ of $\leq 4 \mathrm{~cm} \mathrm{H}_{2} \mathrm{O}$ acceptable for extubation, and the majority consider $\leq 5 \mathrm{~cm}$ acceptable.

The majority of physicians, 94.5\% (381/403), report performing a SBT mainly using CPAP and pressure support (Fig. 1). The majority of the responders, 83\% (344/414), do not perform a RSBI prior to extubation; and among the $17 \%(70 / 414)$ of physicians who perform a RSBI, 51\% (36/70) perform the test with a pressure support that is adapted to the size of the endotracheal tube, $54 \%$ (31/57) consider the upper limit of $\leq 10$ breaths $/ \mathrm{min} /$ $\mathrm{mL} / \mathrm{kg}$ as acceptable for extubation and the majority consider $\leq 12$ breaths $/ \mathrm{min} / \mathrm{mL} / \mathrm{kg}$ as acceptable.

The majority, 62\% (257/416) assess their patients clinically without using a formal sedation score. Overall, 38\% (159/416) use a sedation score. Twenty percent (85/416) use the Glasgow coma score, $18.8 \%$ (78/416) use the COMFORT scale, and $18.5 \%$ (77/416) use other scales.

\section{Attitudes Toward Extubation Readiness Tests}

Quantification of secretions and checking for air leak test had the highest agreement (Fig. 2). There was a statistically significant difference in the respondents' overall responses to the 5 different tests $(P<.001)$. 


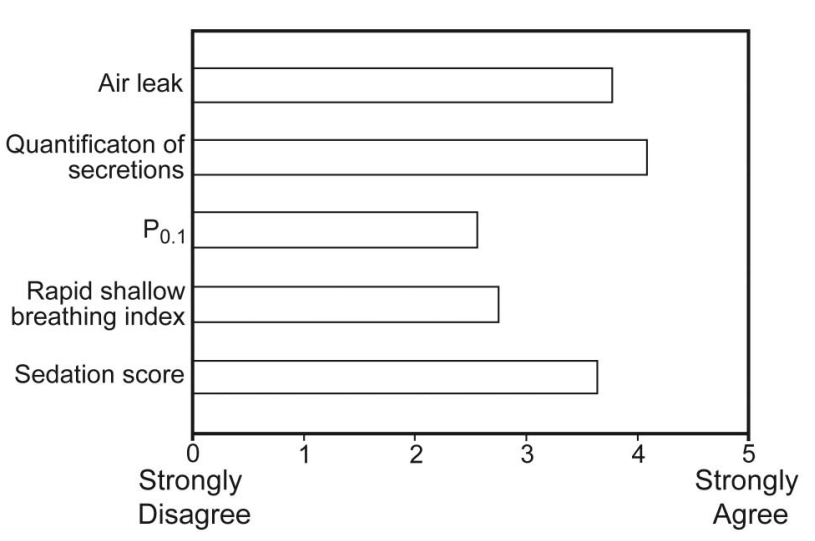

Agreement to Perform

Extubation Readiness Tests

Fig. 2. Likert-scale agreement ratings regarding the use of extubation readiness parameters by pediatric critical care physicians. There is a statistically significant difference in the responses: $P<.001$ via the Friedman 2-way analysis of variance by rank. $\mathrm{P}_{0.1}=$ airwayocclusion pressure $0.1 \mathrm{~s}$ after the start of inspiratory flow.

\section{Decision to Use and Frequency of Use of Extubation Readiness Tests}

Twenty-one percent (84/408) of the responders always perform SBT, and 9\% (37/408) never perform SBT $(P<.001)$. In preparation for termination of mechanical ventilation, $76 \%(309 / 408)$ daily wean the ventilator rate and/or the pressure support, and extubate when the patient is ready, 6\% (24/408) perform daily SBT and extubate when the patient is ready, and 18\% (75/408) perform both daily weaning and SBT.

Most physicians check the amount of tracheal secretions, followed by air leak test, and sedation score (Fig. 3). There was a statistically significant difference in the responses about the 5 tests $(P<.001)$. Overall, 36\% (150/415) of all respondents always check for air leak test, $62 \%(259 / 415)$ always check the amount of tracheal secretions, $0.5 \%$ (2/415) always measure $\mathrm{P}_{0.1}, 2.4 \%(10 / 415)$ always calculate the RSBI, and 23\% (96/415) always use a sedation score prior to extubation.

The only significant difference between physicians with different years of experience was in the use of CPAP during SBT: $12 \%$ (12/99) of the respondents with $<5$ years of practice perform SBT with CPAP, versus $22 \%$ (70/317) of the respondents with $\geq 5$ years of practice $(P=.03)$.

There were significant differences in response to the same question between physicians belonging to a given institution (coefficient of variation range $0-100 \%$ ).

\section{Discussion}

Most of our respondents perform SBT, check for air leak, and assess tracheal secretions prior to extubation. The majority perform daily weaning of the ventilator rate and/or the pressure support, and fewer perform daily SBT.

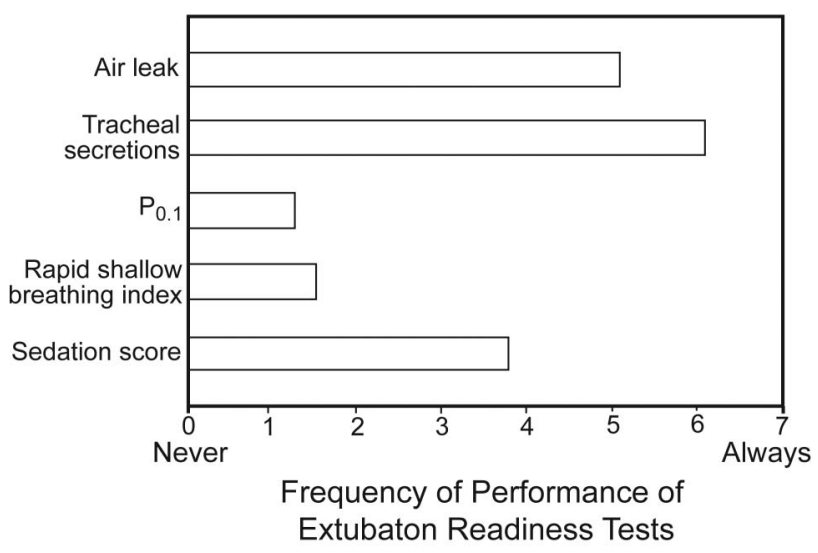

Fig. 3. Likert-scale self-report of the frequency of use of extubation readiness parameters by pediatric critical care physicians. There is a statistically significant difference in the responses: $P<.001$ via the Friedman 2-way analysis of variance by rank. $\mathrm{P}_{0.1}=$ airway-occlusion pressure $0.1 \mathrm{~s}$ after the start of inspiratory flow.

The pediatric literature addressing extubation readiness parameters and strategies to wean off mechanical ventilation is limited, ${ }^{3}$ in contrast to the extensive adult-patients literature. ${ }^{15}$ In adults SBTs are commonly used. ${ }^{16}$ In children SBTs have been shown to be feasible, to have a high sensitivity for predicting extubation success, and to shorten mechanical ventilation. ${ }^{5,17,18}$ The results of the present survey partly reflect the available pediatric literature and suggest a need for further investigations on the barriers that prevent physicians from adopting daily SBT over traditional daily weaning, and support the need for future randomized controlled studies to validate the utility of such tests.

The use of pressure support adjusted for endotracheal tube size has been advocated to overcome endotracheal tube resistance during an extubation readiness trial. ${ }^{12}$ However, performing the SBT with the pressure support set at a higher level for a smaller endotracheal tube can overestimate readiness for extubation in children. ${ }^{19}$ The responses to our survey reflect the uncertainty regarding the performance of SBTs. In adults an elevated RSBI predicts failure, ${ }^{15,16}$ whereas in children the performance and outcomes of RSBI are under debate. ${ }^{3,13,20}$ Our results reflect the limited and conflicting pediatric literature on RSBI in children.

Upper-airway obstruction is one of the major causes of extubation failure in children. ${ }^{8}$ Air leak test is usually used to predict upper-airway obstruction following extubation. In adults, several studies have shown that the air leak test can predict post-extubation stridor. ${ }^{21-23}$ In children the air leak test can predict post-extubation stridor without necessarily predicting extubation failure or success. ${ }^{24} \mathrm{~A}$ previous survey found that the majority of physicians would delay extubation and recommend steroids if there was no evidence of air leak at $30 \mathrm{~cm} \mathrm{H}_{2} \mathrm{O} .{ }^{25}$ However, when studied, an air leak pressure of $\geq 30 \mathrm{~cm} \mathrm{H}_{2} \mathrm{O}$ did not predict extubation failure or outcome. ${ }^{26}$ The present survey re- 


\section{The Use of Extubation Readiness Parameters}

flects that most physicians are concerned about postextubation stridor, despite the lack of evidence that air leak predicts extubation success or failure.

In children, the amount of secretions that predict extubation failure has not been studied. In adults, although moderate to copious tracheal secretions predict extubation failure, ${ }^{27,28}$ only a few physicians rely on the amount of secretions as an extubation readiness parameter. ${ }^{29}$ Quantifying secretions is difficult. Secretions can be assessed semi-quantitatively based on the required frequency of suctioning: once every $2-4$ hours, once every 1-2 hours, or several times per hour. ${ }^{27}$ Secretions can also be assessed with an acoustic secretion detector that indicates the need for suctioning before the patient shows manifest signs of respiratory distress. ${ }^{30}$ The present survey reflects the importance of tracheal secretions in the decision making for critically ill children.

Excessive or inadequate sedation can be detrimental in mechanically ventilated children. In children, continuous sedation is associated with longer mechanical ventilation, ${ }^{31}$ whereas daily interruption of sedation is associated with shorter mechanical ventilation. ${ }^{32}$ Altered mental status and absence of airway reflexes at the time of extubation are associated with extubation failure in children, ${ }^{33}$ but inadequate sedation is also associated with unplanned extubation and post-extubation stridor. ${ }^{34}$ The majority of our respondents consider sedation an important element in extubation readiness but do not use a formal standardized sedation score; instead they use their own clinical judgment. This finding underlines the importance of developing a standardized, easy to use sedation score that can be adopted by most physicians to standardize care.

$\mathrm{P}_{0.1}$ is an index of respiratory center output and neuromuscular drive, and correlates well with the mechanical output of the inspiratory muscles. ${ }^{35,36}$ In a few studies $\mathrm{P}_{0.1}$ was useful in setting the optimal pressure support and predicting extubation success in adults, ${ }^{37-39}$ and in assessing respiratory drive and muscle function, and predicting extubation failure in children. ${ }^{40}$ However, in other studies $\mathrm{P}_{0.1}$ was a poor predictor of extubation failure in adults..$^{41,42}$ The results of our survey reflect the literature.

\section{Limitations}

Our response rate was only $44.1 \%$, despite attempts to improve the response rate. However, our rate was similar to that of other surveys of the same population, ${ }^{43,44}$ and the responses reflect well the pediatric literature. A potential explanation for the low response rate could be that some of the e-mail addresses we obtained belonged to non-practicing individuals. We could not obtain e-mail addresses for many physicians we identified. We surveyed only practicing physicians in academic centers, and our results might have differed if we had included non-academic physicians. We targeted academic physicians because their responses most probably reflect the current teaching of fellows and physicians in training. Also, it is possible that the physicians who responded have a special interest in the topic, which could have biased our results. And, as with any survey, what clinicians say they do may not be what they really do.

\section{Conclusions}

Most respondents check for air leak and assess tracheal secretions prior to extubation. The majority daily wean the ventilator rate and/or the pressure support. Fewer perform daily SBT. Future studies are needed to determine the best extubation readiness tests, in order to develop consensus guidelines.

\section{REFERENCES}

1. US Department of Health \& Human Services; Agency for Healthcare Research and Quality. 2006 Hospital stays for children onlyprincipal procedure only. Outcomes by patient and hospital characteristics for CCS principal procedure category. Respiratory intubation and mechanical ventilation. http://hcupnet.ahrq.gov/ HCUPnet.jsp. Accessed January 6, 2014.

2. US Department of Health \& Human Services; Agency for Healthcare Research and Quality. 1997 Hospital stays for children only - principal procedure only. Outcomes by patient and hospital characteristics for CCS principal procedure category. Respiratory intubation and mechanical ventilation. http://hcupnet.ahrq.gov/HCUPnet.jsp. Accessed January 6, 2014.

3. Newth CJ, Venkataraman S, Willson DF, Meert KL, Harrison R, Dean JM, et al. Weaning and extubation readiness in pediatric patients. Pediatr Crit Care Med 2009;10(1):1-11.

4. Esteban A, Alía I, Gordo F, Fernandez R, Solsona JF, Vallverdú I, et al; Spanish Lung Failure Collaborative Group. Extubation outcome after spontaneous breathing trials with T-tube or pressure support ventilation. Am J Respir Crit Care Med 1997;156(2 Pt 1):459-465.

5. Farias JA, Retta A, Alía I, Olazarri F, Esteban A, Golubicki A, et al. A comparison of two methods to perform a breathing trial before extubation in pediatric intensive care patients. Intensive Care Med 2001;27(10):1649-1654.

6. Epstein SK, Ciubotaru RL, Wong JB. Effect of failed extubation on the outcome of mechanical ventilation. Chest 1997;112(1):186-192.

7. Epstein SK, Nevins ML, Chung J. Effect of unplanned extubation on outcome of mechanical ventilation. Am J Respir Crit Care Med 2000;161(6):1912-1916.

8. Kurachek SC, Newth CJ, Quasney MW, Rice T, Sachdeva RC, Patel NR, et al. Extubation failure in pediatric intensive care: a multiple center study of risk factors and outcomes. Crit Care Med 2003; 31(11):2657-2664

9. Little LA, Koenig JC Jr., Newth CJ. Factors affecting accidental extubations in neonatal and pediatric intensive care patients. Crit Care Med 1990;18(2):163-165.

10. Brochard L, Rauss A, Benito S, Conti G, Mancebo J, Rekik N, et al. Comparison of three methods of gradual withdrawal from ventilatory support during weaning from mechanical ventilation. Am J Respir Crit Care Med 1994;150(4):896-903.

11. Esteban A, Frutos F, Tobin MJ, Alía I, Solsona JF, Valverdú I, et al; Spanish Lung Failure Collaborative Group. A comparison of four methods of weaning patients from mechanical ventilation. N Engl J Med 1995;332(6):345-350.

12. Randolph AG, Wypij D, Venkataraman ST, Hanson JH, Gedeit RG, Meert KL, et al. Effect of mechanical ventilator weaning protocols 
on respiratory outcomes in infants and children: a randomized controlled trial. JAMA 2002;288(20):2561-2568.

13. Farias JA, Alía I, Retta A, Olazarri F, Fernandez A, Esteban A, et al. An evaluation of extubation failure predictors in mechanically ventilated infants and children. Intensive Care Med; 2002;28(6):752-757.

14. Cain M, Mittman R; California Healthcare Foundation. Diffusion of innovation in health care. May 2002. http://www.chcf.org/publications/ 2002/05/diffusion-of-innovation-in-health-care. Accessed January 6, 2014.

15. MacIntyre NR, Cook DJ, Ely EW Jr, Epstein SK, Fink JB, Heffner $\mathrm{JE}$, et al. Evidence-based guidelines for weaning and discontinuing ventilatory support: a collective task force facilitated by the American College of Chest Physicians; the American Association for Respiratory Care; and the American College of Critical Care Med Chest 2001;120(6 Suppl):375S-395S.

16. MacIntyre NR. Evidence-based ventilator weaning and discontinuation. Respir Care 2004;49(7):830-836.

17. Chavez A, dela Cruz R, Zaritsky A. Spontaneous breathing trial predicts successful extubation in infants and children. Pediatr Crit Care Med 2006;7(4):324-328.

18. Foronda FK, Troster EJ, Farias JA, Barbas CS, Ferraro AA, Faria LS, et al. The impact of daily evaluation and spontaneous breathing test on the duration of pediatric mechanical ventilation: a randomized controlled trial. Crit Care Med 2011;39(11):2526-2533.

19. Ferguson LP, Walsh BK, Munhall D, Arnold JH. A spontaneous breathing trial with pressure support overestimates readiness for extubation in children. Pediatr Crit Care Med 2011;12(6):e330-e335.

20. Venkataraman ST, Khan N, Brown A. Validation of predictors of extubation success and failure in mechanically ventilated infants and children. Crit Care Med 2000;28(8):2991-2996.

21. Jaber S, Chanques G, Matecki S, Ramonatxo M, Vergne C, Souche $\mathrm{B}$, et al. Post-extubation stridor in intensive care unit patients. Risk factors evaluation and importance of the cuff-leak test. Intensive Care Med 2003;29(1):69-74.

22. De Bast Y, De Backer D, Moraine JJ, Lemaire M, Vandenborght C, Vincent JL. The cuff leak test to predict failure of tracheal extubation for laryngeal edema. Intensive Care Med 2002;28(9):1267-1272.

23. Miller RL, Cole RP. Association between reduced cuff leak volume and postextubation stridor. Chest 1996;110(4):1035-1040.

24. Mhanna MJ, Zamel YB, Tichy CM, Super DM. The "air leak" test around the endotracheal tube, as a predictor of postextubation stridor, is age dependent in children. Crit Care Med 2002;30(12):2639-2643.

25. Foland JA, Super DM, Dahdah NS, Mhanna MJ. The use of the air leak test and corticosteroids in intubated children: a survey of pediatric critical care fellowship directors. Respir Care 2002;47(6):662-666.

26. Wratney AT, Benjamin DK Jr, Slonim AD, Hamel DS, Cheifetz IM. the endotracheal tube air leak test does not predict extubation outcome in critically ill pediatric patients. Pediatr Crit Care Med 2008; 9(5):490-496

27. Mokhlesi B, Tulaimat A, Gluckman TJ, Wang Y, Evans AT, Corbridge TC. Predicting extubation failure after successful completion of a spontaneous breathing trial. Respir Care 2007;52(12):1710-1717.

28. Khamiees M, Raju P, DeGirolamo A, Amoateng-Adjepong Y, Manthous CA. Predictors of extubation outcome in patients who have successfully completed a spontaneous breathing trial. Chest 2001;120(4):1262-1270.
29. Tulaimat A, Mokhlesi B. Accuracy and reliability of extubation decisions by intensivists. Respir Care 2011;56(7):920-927.

30. Lucchini A, Zanella A, Bellani G, Gariboldi R, Foti G, Pesenti A, Fumagalli R. Tracheal secretion management in the mechanically ventilated patient: comparison of standard assessment and an acoustic secretion detector. Respir Care 2011;56(5):596-603.

31. Payen V, Jouvet P, Lacroix J, Ducruet T, Gauvin F. Risk factors associated with increased length of mechanical ventilation in children. Pediatr Crit Care Med 2012;13(2):152-157.

32. Gupta K, Gupta VK, Muralindharan J, Singhi S. Randomized controlled trial of interrupted versus continuous sedative infusions in ventilated children. Pediatr Crit Care Med 2012;13(2):131-135.

33. Khan N, Brown A, Venkataraman ST. Predictors of extubation success and failure in mechanically ventilated infants and children. Crit Care Med 1996;24(9):1568-1579.

34. Grant MJ, Scoppettuolo LA, Wypij D, Curley MA, RESTORE Investigative Team. Prospective evaluation of sedation-related adverse events in pediatric patients ventilated for acute respiratory failure. Crit Care Med 2012;40(4):1317-1323.

35. Iotti GA, Brunner JX, Braschi A, Laubscher T, Olivei MC, Palo A, et al. Closed-loop control of airway occlusion pressure at 0.1 second (P0.1) applied to pressure-support ventilation: algorithm and application in intubated patients. Crit Care Med 1996;24(5):771-779.

36. Perrigault PF, Pouzeratte YH, Jaber S, Capdevila XJ, Hayot M, Boccara G, et al. Changes in occlusion pressure (P0.1) and breathing pattern during pressure support ventilation. Thorax 1999;54(2):119123.

37. Alberti A, Gallo F, Fongaro A, Valenti S, Rossi A. P0.1 is a useful parameter in setting the level of pressure support ventilation. Intensive Care Med 1995;21(7):547-553.

38. Capdevila XJ, Perrigault PF, Perey PJ, Roustan JP, d'Athis F. Occlusion pressure and its ratio to maximum inspiratory pressure are useful predictors for successful extubation following T-piece weaning trial. Chest. 1995;108(2):482-489.

39. Hilbert G, Gruson D, Portel L, Vargas F, Gbikpi-Benissan G, Cardinaud JP. Airway occlusion pressure at $0.1 \mathrm{~s}$ (P0.1) after extubation: an early indicator of postextubation hypercapnic respiratory insufficiency. Intensive Care Med 1998;24(12):1277-1282.

40. Manczur TI, Greenough A, Pryor D, Rafferty GF. Assessment of respiratory drive and muscle function in the pediatric intensive care unit and prediction of extubation failure. Pediatr Crit Care Med 2000;1(2):124-126.

41. Conti G, Montini L, Pennisi MA, Cavaliere F, Arcangeli A, Bocci MG, et al. A prospective, blinded evaluation of indexes proposed to predict weaning from mechanical ventilation. Intensive Care Med 2004;30(5):830-836

42. Fernandez R, Raurich JM, Mut T, Blanco J, Santos A, Villagra A. Extubation failure: diagnostic value of occlusion pressure (P0.1) and P0.1-derived parameters. Intensive Care Med 2004;30(2):234-240.

43. Needle JS, Mularski RA, Nguyen T, Fromme EK. Influence of personal preferences for life-sustaining treatment on medical decision making among pediatric intensivists. Crit Care Med 2012;40(8):24642469.

44. Hart JL, Kohn R, Halpern SD. Perceptions of organ donation after circulatory determination of death among critical care physicians and nurses: a national survey. Crit Care Med 2012;40(9):2595-5600.

This article is approved for Continuing Respiratory Care Education credit. For information and to obtain your CRCE

(free to AARC members) visit www.rcjournal.com

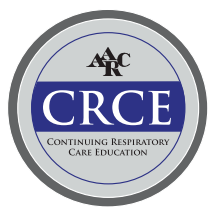

